
Our products and services: cut to the chase

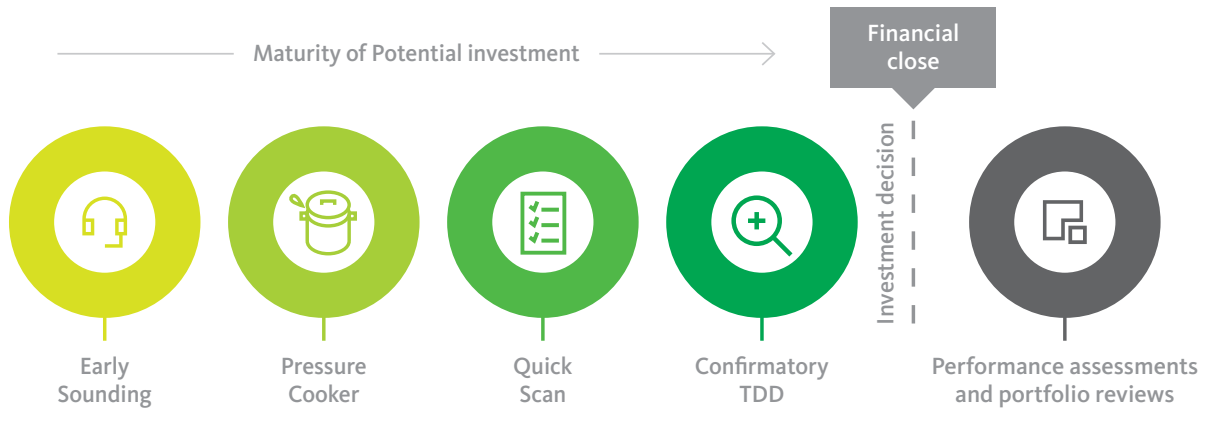

\section{Early Sounding}

- What: A free one hour telephone call to pick the brains of one of our 400 leading experts in cleantech.

- Why: Quickly broaden your understanding of a specific investment thesis or perhaps an area within cleantech.

\section{Pressure Cooker}

- What: An intensive, multiple hour Q\&A session with you, our researchers and possibly your investment target in one room.

- Why: A quick, effective and efficient way of having your most pressing questions answered and getting the big picture right.

\section{Quick Scan}

-What: a high level assessment to identify the key technological risks and pinpoint high-risk areas for further due diligence.

- Why: You are more advanced in your investment decision, and you need to have a clear, high level overview of the biggest risk areas.

\section{Confirmatory Technology Due Diligence}

- What: A comprehensive report, offering a deep understanding of the risks and opportunities as well as mitigation options and strategies, expressed in financial terms where possible.

- Why: Regularly used in project finance or in more sizeable Venture Capital / Private equity deals as the last barrier before a final investment decision can be made.

\section{Performance assessments and portfolio reviews}

- What: Rapid assessment and problem solving (debottlenecking) in technology development and upscaling of existing cleantech investments or portfolio reviews

- Why: You want to optimize the value of your existing investments or you want to know whether the right investments are being made to support an overall investment policy. 